only a modest portion of the demands made on the scheme.

\section{Bedgebury National Pinetum and Forest Plots}

IN 1924 it was decided to form a new pinetum to supplement that in existence at Kew, the latter being threatened by industrial expansion and increasing pollution of the air, and the new pinetum was established at Bedgebury, Kent. Bedgebury Forest lies in undulating country in the eastern part of the Wealden district of south-east England-a pleasant country, the lower levels having good fertile soils, which are well farmed, and the upper areas being well wooded. The pinetum originated under the auspices of the Royal Botanic Gardens and the Forestry Commission, and a committee was set up to manage the place, comprising members of both bodies. Sir Geoffrey Evans, chairman of this committee, writes the foreword to a small pamphlet entitled "Guide to the National Pinetum and Forest Plots at Bedgebury", issued by the Forestry Commission (second edition. Fp. $68+8$ plates. London: H.M.S.O., 1955 ; $3 s .6 d$. net). The guide contains a handy plan which enables the visitor to find his way about with ease. The present plantings were undertaken in 1925 by W. Dallimore, who supervised the work until 1945, and the large collection of conifers which has been assembled in the pinetum is largely due to his unfailing energy and erthusiasm. When he relinquished the post of honorary curator, he remained on the committee, where his advice is of value. Since 1948 the pinetum has been under the care of a resident supervisor, who is also responsible for the forest plots. A car-park is available for visitors, whose numbers far exceed those with specialized interests in the pinetum or the forest plots. It is for this reason that the guide has been published. The pinetum is near London and is a most useful adjunct to Kew that should appeal to all lovers of the Royal Botanic Gardens.

\section{Bardsey Observatory}

Desprte considerable financial difficulties, the Bardsey Bird and Field Observatory continues to make progress and, in its second annual report, accounts are given of numerous activities which took place in 1955. 'This privately owned island lies off the Montgomeryshire coast and, during the year, attracted student parties as well as a number of individual visitors. Besides many ornithological studies, visitors carried out observations on the earthworms and the littoral and sublittoral marine algae of the island. The report may be obtained from the honorary secretary, Mr. W. M. Condry, Eglwysfach, near Machynlleth, Mont.

Ejection Theory of the Formation of Meteor Showers

Miroslav Plavec, of the Astronomical Institute of the Czechoslovak Academy of Sciences, Prague, in a paper on the "Orbit of an Ejected Meteor" (Bull. Astro. Inst. Czech., 6, No. 2; 1955), investigates the perturbing effect of the Earth upon meteors ejected by a comet, the ejection occurring, in most cases, in the vicinity of perihelion. In these circumstances the comet's orbital velocity exceeds $30 \mathrm{~km}$. $/ \mathrm{sec}$., and a velocity of ejection less than $3 \mathrm{~km}$./sec. is assumed; on physical grounds, it is believed that velocities greater than this are improbable. The theory is developed and then applied to three meteor showers-the Geminids,
Draconids and Lyrids-and it is assumed that all available directions of ejection are possible. The deviations from the elements of the new orbits are extremely small except in the case of the period of revolution, and, in addition, the differences in the perihelion passages accumulate in time, so that meteors are rapidly separated from the comet. The most interesting of these three showers is the Draconid shower, associated with comet GiacobiniZinner, and it is shown that a meteor ejected with a velocity of only $10 \mathrm{~m} . / \mathrm{sec}$., in the direction of motion of the comet, returns to perihelion eleven days later than the comet. After about seven revolutions such a meteor would be as far from the comet as the meteors were when observed during the 1933 shower - that is, eighty days. It is also shown that small differences of ejection velocities between individual meteors would produce a dispersal along the orbit, and here is seen that general tendency of an ejected meteor cloud to form a fairly homogeneous ring along the whole orbit.

\section{Co-ordinates of Venus}

As the result of a scheme undertaken in 1947 by the Yale University Observatory, the Watson Scientific Computing Laboratory, and the United States Naval Observatory, with the object of improving our knowledge of the motions of the principal planets, the Naval Observatory has prepared a set of "Co-ordinates of Venus, 1800-2000", published as Vol. 15, Part 3, of "Astronomical Papers prepared for the Use of the American Ephemeris and Nautical Almanac" (Washington, D.C. : Government Printing Office, $1956 ; 2.50$ dollars). The determination of the masses of certain planets and of improved values of certain fundamental astronomical constants was an important part of this undertaking, and for this purpose it was necessary to trace the orbits of selected minor planets with high precision throughout the period since their discovery. Precise coordinates of Venus were essential for calculating the action of this planet on these selected minor planets, and it is explained in the preface why Newcomb's tables were both inconvenient and unsuitable for the accuracy required. The completion of the extensive calculations at the Cincinnati Observatory was made possible through a generous grant from the International Business Machines Corporation, and this grant provided for an installation of punched-card equipment devoted exclusively to scientific computation. Additional equipment for this project was obtained by contract with the Mathematics Division of the Office of Naval Research. Details of the method of computation, etc., with formulæ and numerical examples, are provided in the publication. The heliocentric co-ordinates of Venus are given from Dec. $27 \cdot 5$ d., 1799 , to Dec. $22 \cdot 0$ d., 2000 , Julian Days $2,378,492 \cdot 5$ to $2,451,692 \cdot 5$. The longitude is given to mean equinox of date and also to equinox $1950 \cdot 0$, and the latitude to the ecliptic of date and to the ecliptic of $1950 \cdot 0$. In addition, the radius vector and rectangular co-ordinates (equinox and equator $1950 \cdot 0$ ) are given to seven decimal places.

\section{Vacuum in Metallurgy}

A. A. Vertman and L. M. Novik (Priroda, No. 9, 81 ; 1956) give an account of laboratory and industrial experience in the smelting and casting of metals under vacuum. It is a well-known fact that many defects of cast metals are due to the occluded or dissolved gases, such as nitrogen, oxygen and hydro. 